GM was highest among bogger operators $0.53 \mathrm{mg} / \mathrm{m}^{3}$ $(G S D=0.27)$ and the least among truck operators 0.29 $(G S D=0.37)$. While for open pit, the highest GM was found among quality controllers $0.39 \mathrm{mg} / \mathrm{m}^{3} \quad(\mathrm{GSD}=0.18)$ and the least among in truck operators $0.13 \mathrm{mg} / \mathrm{m}^{3}(\mathrm{GSD}=0.15)$. Respiratory symptoms were phlegm (49.1\%), Breathlessness (42.9\%), cough (37.5\%), wheezing (18.8\%) and chest tightness $(10.7 \%)$. Prevalence of airflow obstruction (FEV1/FVC $<0.75$ ) was $7.7 \%$ among non smoking miners.

Discussion Despite the fact that levels of respirable dust exposure were below recommended occupational exposure limits, prevalence of respiratory symptoms was still high among gold miners. There is a need to conduct further studies on quarts.

\section{EFFECTIVENESS OF PARTICIPATORY ERGONOMIC INTERVENTIONS AND A MUSCULOSKELETAL DISORDER PREVENTION PROGRAM ON THE REDUCTION OF MUSCULOSKELETAL RISK-FACTORS IN CORE-SHACK OPERATIONS}

\author{
${ }^{1,2} \mathrm{~K}$ Whelan, ${ }^{1,2} \mathrm{~T}$ Eger. 'Laurentian University, Sudbury, Canada; ${ }^{2}$ Centre for Research in \\ Occupational Safety and Health, Sudbury, Canada

\subsection{6/oemed-2018-ICOHabstracts.711}

Introduction Workplace musculoskeletal disorders (WMSDs) give rise to approximately $44 \%$ of compensation claims each year within the Canadian mining sector. Despite the immensity of reported WMSDs little research has been conducted within said population. The purpose of this study is to examine the effectiveness of physical ergonomic interventions and a participatory MSD prevention program on the reduction of MSD risk-factors within core-shack operators. Anecdotal evidence suggests that the awkward postures, excessive force requirements, and repetitive material handling found within coreshack operations may be placing workers at a greater risk for MSD development; however, no previous research has been conducted.

Methods Amalgamation of observational based MSD screening tools and direct joint-angle measurements via a mobile movement analysis and motion capture system (NOTCH) will be used. Siemens Classic Jack human modelling software will be utilised to provide ergonomic assessments within a simulated environment. Resultant data will be used to develop targeted physical ergonomic interventions to mitigate MSD risk-factors within at-risk tasks. The Occupational Health and Safety Council of Ontario (OHSCO) MSD Prevention Toolbox 3C and New South Wales Mine Safety and Advisory Committee MSD Prevention Guide will be used as a reference for the development of a participatory MSD Prevention Program.

Result It is anticipated that the implementation of targeted workplace ergonomic interventions in conjunction with a participatory MSD prevention program will provide a comprehensive approach to MSD risk factor identification and prevention strategies. Moreover, it is expected that the intervention components will increase communication and decision latitude within core-shack operations.

Discussion The prevalence of musculoskeletal injuries with the Canadian mining industry is of particular concern. The dissemination of this study will be shared with participating mines so improvements can be made to aide in worker health and safety and prevention of musculoskeletal injuries.
40

PROMOTING HEALTHY LIFESTYLES IN AN OPEN PIT COAL MINE

H Piedrahita. Carbones del Cerrejón, Limited - Colombia

\subsection{6/oemed-2018-ICOHabstracts.712}

Introduction Open pit coal mines face different occupational risks, however little attention has been placed on the importance of promoting in the labour and social sphere of workers healthy lifestyles. In an open coal mine in Colombia and with the goal to prevent general and occupational diseases and overall to improve quality of life, was developed a participatory and integrated program focused in promoting healthy lifestyles.

Methods A company team spent nearly six months in the first half of 2013 in developing the program. The team comprised members of the Occupational Health Committee, leaders from the trade union and representatives from various operational and administrative areas. The final outcome of this preparatory work was the model guiding this program, which has three main central and transverse pillars: physical activity, healthy nutrition, and related education. Physical activity is the model's most important bulwark.

Result The program was finally implemented in 2015 in all the settlements of region where the workers reside reaching an adherent level of 1818 people, demonstrating its widespread acceptance amongst employees and their families. In 2017 there are more than 3000 participants and at the end of 2016, despite the short period since implementation, overweight and obesity levels had fallen by $3.75 \%$ and triglyceride levels had dropped by $6.9 \%$ (cholesterol was unchanged). Program adherence has remained steady at $70 \%$ since the start of the pilot test as well as throughout the year and a half of the program itself.

Discussion Considering that other similar initiatives reach maximums of $45 \%-50 \%$, this program's adherence is quite successful. Throughout 2015 and 2016, there were more than 100,200 hours of activities with 91710 participant attendances. The program has strengthened ties amongst the participants and communities involved, which has been reflected in interactions on social networks showing various activities held at different locations.

\section{HEALTH AND SAFETY TRAINING ON LEAD EXPOSURE FOR ARTISANAL AND SMALL-SCALE GOLD MINERS IN ZAMFARA STATE, NIGERIA}

${ }^{1}$ Kadiri Shamusideen*, ${ }^{2}$ Sels Dakwak. 'Principal Consultant, Zub Chord Technical Ventures, Lagos Nigeria; ${ }^{2}$ Deputy Director, Industrial Training Fund, Jos Nigeria

\subsection{6/oemed-2018-ICOHabstracts.713}

Introduction Artisanal and small-scale gold mining (ASGM) has long been practiced in Nigeria. Mining often involves both occupational and community health and safety hazards that not only affect miners, but also their families and communities. In Zamfara, Nigeria where the gold bearing deposits contain unusually problematic concentrations of lead these are overwhelmed by the enormous effects of lead poisoning. In 2010, unregulated small-scale miners in Zamfara state, gave rise to an epidemic of childhood lead poisoning, with at least four hundred children under the age of five dying within a six-month period (a number that rose to over 700 by 2013). It was found out that a lack of training in Health and safety and support to the ASGM sector, and the need for the miners 